\title{
El vinagre de plátano en el desarrollo de la cocina local manabita
}

\section{Banana vinegar in the development of local manabita cuisine}

1 Joselyn Tatiana Escalante Loor

https://orcid.org/0000-0001-9191-6572

Universidad Técnica de Ambato, Facultad de Ciencias de la Educación, Carrera de Turismo. Ambato, Ecuador jescalante5996@uta.edu.ec

2 Camilo Francisco Torres Oñate

https://orcid.org/0000-0002-9411-5401

Universidad Técnica de Ambato, Facultad de Ciencias de la Educación, Carrera de Turismo. Ambato, Ecuador cf.torres@uta.edu.ec

3 María Fernanda Viteri Toro (iD) https://orcid.org/0000-0003-2600-7115 Universidad Técnica de Ambato, Facultad de Ciencias de la Educación, Carrera de Turismo. Ambato, Ecuador mf.viteri@uta.edu.ec

4 Diana Alexandra Falcón Salazar iD https://orcid.org/0000-0002-8980-3357 Universidad Regional Autónoma de Los Andes, Facultad de Dirección de Empresas, Carrera de Turismo. Ambato, Ecuador ua.dianafalcon@uniandes.edu.ec

Artículo de Investigación Científica y Tecnológica Enviado: 24/12/2021

Revisado: 29/12/2021

Aceptado: $12 / 01 / 2022$

Publicado:08/03/2023

DOI: https://doi.org/10.33262/concienciadigital.v6i1.4.1998

Cítese:

Escalante Loor, J. T., Torres Oñate, C. F., Viteri Toro, M. F., \& Falcón Salazar, D. A. (2023). El vinagre de plátano en el desarrollo de la cocina local manabita. ConcienciaDigital, $6(1.4)$, 287-297. https://doi.org/10.33262/concienciadigital.v6i1.4.1998

CONCIENCIA DIGITAL, es una Revista Multidisciplinar, Trimestral, que se publicará en soporte electrónico tiene como misión contribuir a la formación de profesionales competentes con visión humanística y crítica que sean capaces de exponer sus resultados investigativos y científicos en la misma medida que se promueva mediante su intervención cambios positivos en la sociedad. https://concienciadigital.org

La revista es editada por la Editorial Ciencia Digital (Editorial de prestigio registrada en la Cámara Ecuatoriana de Libro con No de Afiliación 663) www.celibro.org.ec

Esta revista está protegida bajo una licencia Creative Commons Attribution Non Commercial No Derivatives 4.0 International. Copia de la licencia: http://creativecommons.org/licenses/by-nc-nd/4.0/ 
Palabras claves:

local, criolla,

Manabí, ancestral, vinagre, plátano, comida

\section{Keywords:} local, Creole, Manabí, ancestral, vinegar, banana, food.

\section{Resumen}

Introducción: El presente proyecto de investigación se enfoca en la comida local manabita, principalmente en uno de los elementos que le dan su identidad legendaria como es el vinagre de plátano, que actualmente está siendo dejado en el olvido como parte del conocimiento ancestral en la elaboración de la comida típica y se evidenciará como ambos, gastronomía y vinagre, sí están fuertemente afianzados con el desarrollo de la misma, es un condimento que muy pocas personas conocen, que fue y ha sido parte del progreso de la comida criolla en Manabí por generaciones y evolucionó en sus usos tanto como la gente misma de la provincia. Objetivo: Determinar el desarrollo de la cocina local manabita con el ingrediente de vinagre de plátano Metodología: El diseño de la investigación es bibliográfica-documental o "De Hecho" porque apoya sus conceptos en contenido investigativo y científico. La encuesta sensorial fue aplicada a 20 individuos con edades comprendidas entre los 20 a 70 años y para calcular la variable se usó el programa SPSS Resultados: La prueba estadística que se usó para la verificación de hipótesis fue el análisis de dos vías de Friedman y se concluyó que el vinagre de plátano tiene un impacto sensorial en las preparaciones es por ellos que la mayoría de los encuestados prefirieron las preparaciones con proteínas tradicionalmente conocidas y más usadas, además se comprobó que el uso del vinagre contribuye al desarrollo de la comida local manabita

\section{Abstract}

Introduction: The present research project focuses on the local food manabita, mainly on one of the elements that give it its legendary identity as is the banana vinegar, that is currently being forgotten as part of the ancestral knowledge in the elaboration of the typical food and will be evidenced as both, gastronomy and vinegar, are strongly entrenched with the development of the same, is a condiment that very few people know, that went and has been part of the progress of Creole food in Manabí for generations and evolved in its uses as much as the people themselves of the province. Objective: To determine the development of the local cuisine manabita with the ingredient of banana vinegar Methodology: The design of the research is bibliographic documentary because it supports it concepts in research and 
scientific content. The sensory survey was applied to 20 individuals aged between 20 and 70 years and the SPSS program was used to calculate the variable Results: The statistical test that was used for hypothesis verification was Friedman's two-way analysis and it was concluded that banana vinegar has a sensory impact on preparations is by them that most of the respondents preferred protein preparations traditionally known and more widely used, it was also found that the use of vinegar contributes to the development of local food manabita

\section{Introducción}

Este proyecto de investigación tiene mucha importancia debido a que actualmente un gran número de las antiguas tradiciones culinarias ancestrales se han perdido, las generaciones modernas escogen poner la sazón a las comidas a con productos muy procesados y repletos de elementos químicos, por ejemplo, los famosos "caldos concentrados" de pollo, res, etc. La motivación principal de este proyecto de investigativo es intentar mantener y recordar a la gente los sabores que otorgaron a la provincia de Manabí el renombre de tener una de las mejores gastronomías del Ecuador.

La popularidad que conserva Manabí a lo que sus deliciosos manjares se refiere se debe a que los habitantes de este mágico lugar desde hace mucho tiempo realizaron procesos poco comunes en el momento de preparar los alimentos, el suero de leche, el aguardiente o el mismo vinagre de plátano son ejemplos de la inventiva local, en este documento académico la autora intenta que las generaciones modernas conozcan los productos que se usan en la gastronomía manabita desde antiguos tiempos, remarcando que en el 18 de octubre del 2018 la Cocina Tradicional Manabita se declaró patrimonio inmaterial del Ecuador todo esto por parte del Instituto Nacional de Patrimonio Cultural, siendo así los beneficiarios indirectos los habitantes de esta región del país, con la información aquí contenida y expuesta es el público en general conocerá un poco más sobre la historia de la tan querida y afamada comida manabita, este documento se conserva en "papel" y de manera responsable el legado de su gastronomía ampliamente reconocida y querida por todo aquel que la prueba.

El conocimiento y la difusión de las prácticas ancestrales de preparación de la comida despierta en quienes se disponen a conocerlas un sentimiento de pertenencia hacia la región e historia que engloban los ingredientes y platos mismos.

Díaz (2020) describe al vinagre como un líquido apto para el consumo humano, elaborado a partir de materias primas naturales que pasan por los procesos de fermentación alcohólica y acética, por lo cual el vinagre se puede obtener de cualquier producto que 
presente azucares en él, pudiendo ser futas, miel, vinos o incluso cerveza en muchos de los casos los productos a usarse.

Las primeras noticias del vinagre son milenarias, se inician en el Medio Oriente, posteriormente se extendieron a lo largo de todo el Mediterráneo y se relacionan con la aparición de los primeros vinos por lo cual este ingrediente es muy antiguo porque está demostrado que muchas culturas arcaicas ya lo usaban no sólo en el campo culinario si no también lo usaban como medicina y hasta para realizar procesos de desinfección.

Según Teneda \& Milla (2018) el vinagre no contiene sal, grasa, previene la contaminación de bacterias en los alimentos, aumenta el sabor de las comidas sirve como remedio casero en la prevención de enfermedades, es producto muy versátil con varios usos, el principal es el de la gastronomía en donde juega un rol fundamental al desinfectar los alimentos y realza los sabores de estos.

No se puede pasar por alto que el vinagre ha sido desde hace mucho tiempo un ingrediente infaltable de la cocina, en muchas civilizaciones que se establecieron a lo largo de la Historia, el vinagre se consideró y considera un condimento ideal para conservar los alimentos, potenciar su sabor, y mantener la consistencia y la calidad de los mismos, al tiempo que compensa las insuficiencias nutricionales convirtiéndolo así uno de los mejores aliados al momento de preparar comestibles como conservas o incluso para optimizar el gusto y sabor de varias recetas crudas o cocinadas.

El vinagre es usado desde la antigüedad como conservante natural por esto se supone que en tiempos pasados los primeros humanos en usar el vinagre se dieron cuenta que servía como más que un simple componente para retrasar y evitar la descomposición de los alimentos y comenzaron a usarlo como condimento que mezclaban con plantas y hasta en los guisos que hacían durante los viajes largos que emprendían.

La fermentación es un proceso en el que están presentes el crecimiento de microorganismos como el moho, bacterias y levaduras esto da pie a que el alimento o producto cambie su sabor y tenga una vida útil más larga, por eso el vinagre no simplemente realza el sabor de las comidas, sino que también contribuye a beneficios en la salud como bacterias y probióticos amigables con el sistema digestivo.

Actualmente la mayor parte del vinagre se obtiene en cultivo de tanque sumergido por lo que sus beneficios y valores organolépticos se aprovechan de mejor manera, aunque siempre habrá quienes no lo consideren así y establecen que el grado de acidez debe ser, como mínimo de 6 grados para ser considerado un vinagre como tal.

Jeambey (2016) piensa que las gastronomías locales, con todo y sus productos y platos típicos, tienen la particularidad de ser un recurso patrimonial activo, que cambia en cada estación del año, esto porque cada determinado tiempo los productos que son 
característicos de cada cambio estacional se vuelven los componentes principales de los platos en las comunidades que los preparan.

Para Molina et al. (2018) hay una relación cercana entre gastronomía y costumbres, sostenidas en la zona rural y que han trascendido a la zona urbana, sin muchas pretensiones de quedarse debido al epistemicidio ocasionado por la ola del modernismo, es decir que se refiere a que la comida local es parte no solo de un modo de vida sino también de la cosmovisión y el sincretismo de los pueblos que se han ido perdiendo a lo largo del tiempo y la migración a las ciudades.

La comida local forma parte de la propiedad intelectual de una región o país, igual que los productos que terminarán mesa siendo así que la comida local tiene una identidad muy remarcada dependiendo de los elementos o ingredientes que formen parte de su estructura.

Los platos típicos de una zona esconden años de tradición, momentos, técnicas y ambientes que los hacen diferentes entre sí, cada preparación cuenta cómo una comunidad ha superado varios acontecimientos que les han formado hasta el día de hoy Valcárcel \& Venegas (2015), por eso la comida local manabita destaca, es muy querida y conocida por sus sabores diferentes y tan acentuados en donde sus principales ingredientes son los productos que crecen en sus fértiles fincas, como fréjol, calabaza, maíz y por supuesto la existente variedad de actividad pecuaria como ganado vacuno, porcino, aviar y caprino, también es importante sus arraigadas costumbres gastronómicas que aún en varios sitios se conservan y prevalecen hasta el día de hoy.

Para Gómez et al. (2016) la comida local es el conjunto de sentimientos y creencias de un grupo relacionadas con una visión de superioridad o de preferencia respecto de todo aquello que viene de su propia cultura, estableciendo así que la comida no solo es para alimentar, sino que también que da un sentido muy afincado de pertenencia en una comunidad no solo un elemento cotidiano más.

La gastronomía ha cambiado con el paso del tiempo, hay una serie de factores que trascienden directamente en la cocina. Factores internos, hábitos y costumbres alimentarias. Y los factores externos se relacionan con el clima, condición social, religión y tecnología (Velasteguí \& Rodríguez, 2017), y es por esta pérdida de identidad gastronómica que varias recetas y sabores muy antiguos y representativos de la comida local manabita son tan particulares.

Las prácticas de cada grupo étnico, en cuanto a la preparación y consumo de alimentos son propios de cada comunidad (Folleco et al., 2019), por eso la comida local manabita es una especialidad en medio del territorio ecuatoriano al tener prácticas de preparación e ingredientes muy auténticos de su territorio, son elementos que no se pueden hallar muy fácilmente en otros sitios. 
Según Unigarro (2015), los conocimientos, saberes y prácticas alimentarias típicas y locales son el resultado de la convivencia entre culturas diferentes, precisamente donde el sincretismo juega un papel muy importante en la cocina local manabita por que como se mencionó anteriormente su singularidad y fama proviene de prácticas y elementos únicos de su cultura y herencia de indígenas y españoles.

La comida de la capital manabita, Portoviejo, fue reconocida como parte de la Red de Ciudades Creativas por la UNESCO (MINTUR, 2019), el sabor y las rectas tradicionales de la ciudad y el resto de la provincia fueron reconocidos por su particularidad en cuanto a sabores e ingredientes usados, por su peculiaridad y sabores tan marcados y exquisitos es bien conocido en todo el Ecuador que la comida de Manabí es una de las mejores del país por eso es que aparece como una de las principales razones para que los turistas se decidan a visitar los atractivos de dicho lugar.

Fernández et al. (2016) aseveran que en la actualidad se busca comidas autóctonas, en donde destaquen los productos animales y vegetales usados por los habitantes nativos de los destinos turísticos, para propiciar una atmósfera distinta que crea experiencias inolvidables por la conexión entre el viajero y el lugar que visita, y eso incluye la manera tradicional de cómo cocinar los alimentos con ingredientes que sea por falta de interés o para ahorrar tiempo y costos han hecho muchas prácticas e ingredientes se olviden, siendo que la autenticidad es lo que más atrae a los visitantes al momento de probar una comida nueva.

\section{Metodología}

En esta parte se trata acerca del empleo de técnicas, métodos y materiales utilizados para la obtención de información requerida además de relevante para el desarrollo del presente proyecto de investigación. Con una descripción detallada sobre los conceptos de métodos usados además de la modalidad y el nivel de la investigación.

Para Sandhusen (2002) las encuestas obtienen información sistemáticamente de los encuestados a por medio de preguntas, ya sean de índole personal, por medio de llamadas telefónicas o por correo. Por lo que para la elaboración de esta encuesta se toman en cuenta los siguientes puntos:

Fichas de análisis sensorial en base del modelo de la cata de vinos en la cava "Montes" en Chile, que por medio de los sentidos detecta las propiedades organolépticas de los vinos en lo que se refiere a color, olor, textura y sabor por lo cual es de los modelos más concisos, se decidió que sería uno de los modelos más idóneos para la recabación de información. Se escogieron 5 preparaciones que incluían el ingrediente principal, el vinagre de plátano, fueron elegidas por ser emblemáticas y de fácil y barata preparación siendo objeto de estudio y cata. 
La encuesta se aplicó a 20 individuos qué aceptaron voluntariamente realizar la degustación de las variadas recetas que incluyen el vinagre como elemento principal de su preparación y que son las más representativas de la comida local manabita. La muestra se compone de individuos con edades comprendidas entre los 20 a 70 años, este rango se eligió para así poder tener los diferentes puntos de vista en cuanto al sabor y demás características de la comida degustada.

\section{Resultados}

Según los resultados obtenidos en la encuesta realizada es claro que el platillo de seco de cerdo es el que prepondera y tiene mayor aceptación entre la mayoría de los individuos por la familiaridad que tiene con la misma, por el contrario del sudado de lengua que fue el que menor aceptación por parte de los encuestados, se puede decir que por no ser una proteína tan utilizada.

\section{Figura 1}

\section{Parámetro color}

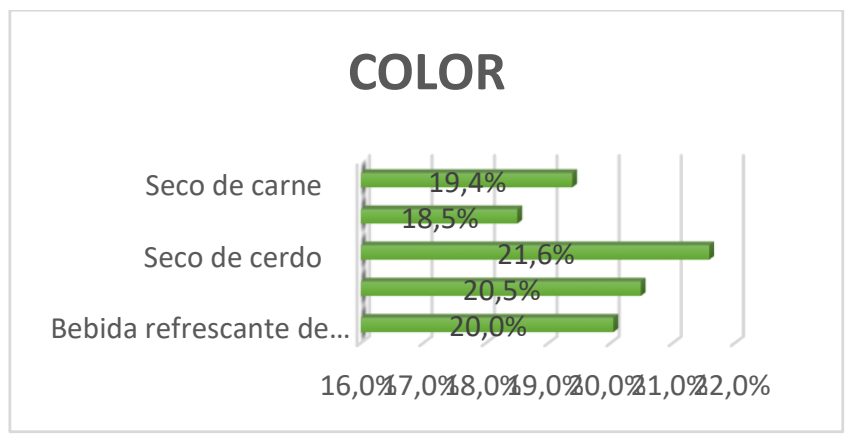

Nota: Datos expresados en porcentaje de preferencia que tuvo cada plato.

\section{Figura 2}

\section{Parámetro Olor}

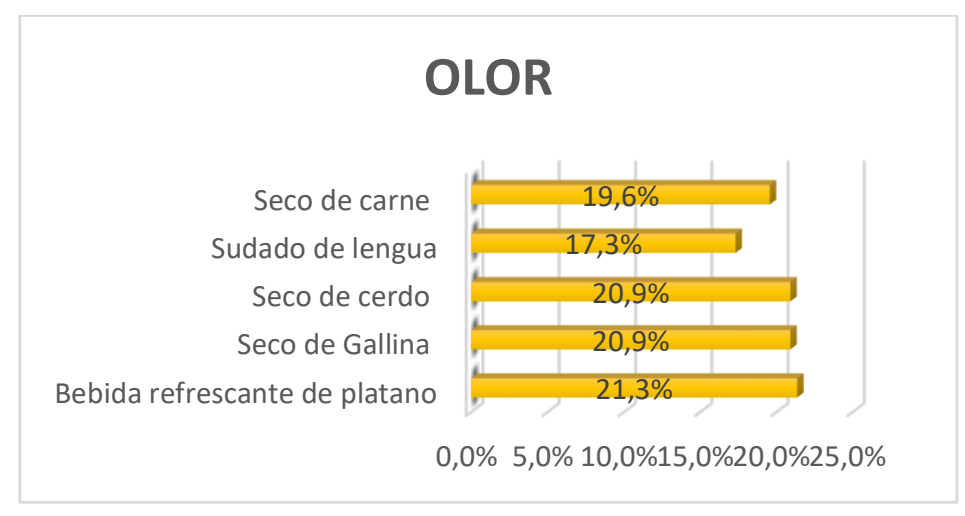

Nota: Datos expresados en porcentaje de preferencia que tuvo cada plato. 
Según los resultados obtenidos en la encuesta realizada es claro que la bebida refrescante de plátano prepondera y tiene mayor aceptación entre la mayoría de los individuos debido a que el golpe de sabor final le provee de un regusto único al momento de beberla, por el contrario del sudado de lengua que fue el que menor aceptación por parte de los encuestados posiblemente por su naturaleza de "víscera" y olor tan característico que tiene.

\section{Figura 3}

\section{Parámetro Textura}

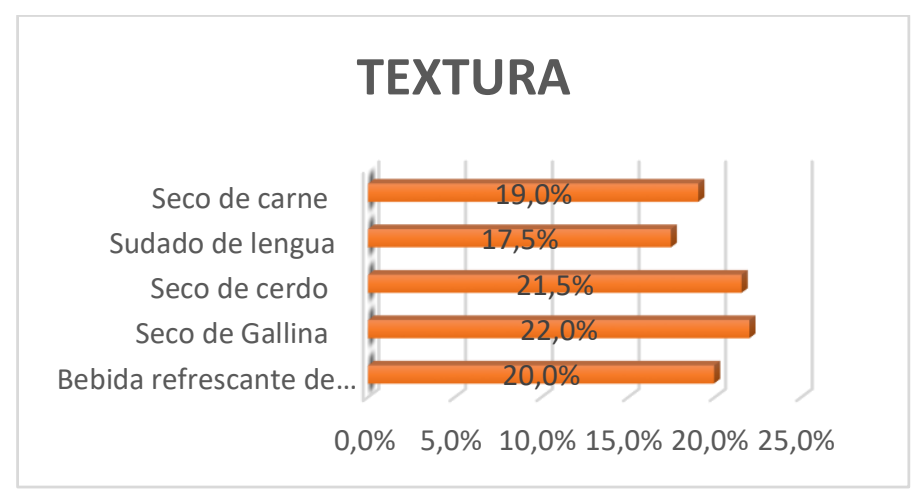

Nota: Datos expresados en porcentaje de preferencia que tuvo cada plato.

Según los resultados obtenidos en la encuesta realizada queda claro que el platillo de seco de gallina es el que prepondera y tiene mayor aceptación entre la mayoría de los individuos puede deberse a la textura tan suave y sabrosa de la carne, por el contrario del sudado de lengua que fue el que menor aceptación por parte de los encuestados posiblemente por lo rugoso y cartilaginoso de la proteína.

\section{Figura 4}

\section{Parámetro sabor}

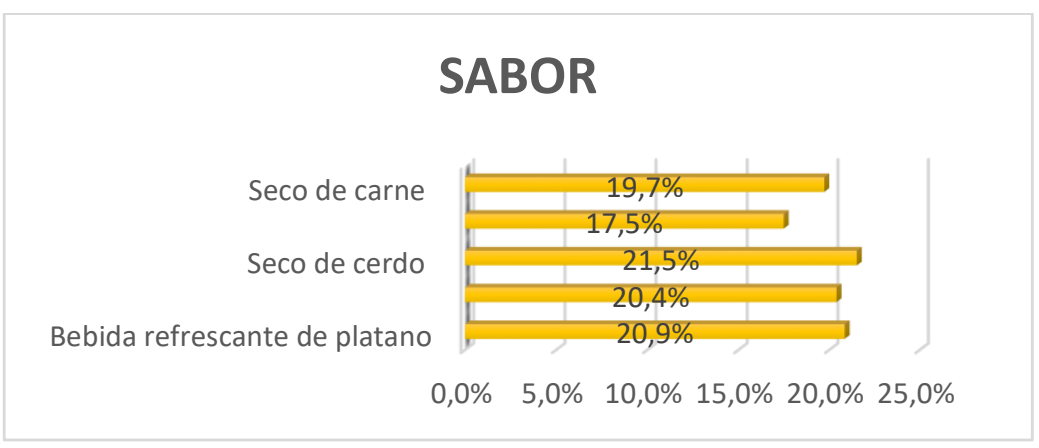

Nota: Datos expresados en porcentaje de preferencia que tuvo cada plato. 
Según los resultados obtenidos en la encuesta realizada queda claro que el platillo de seco de cerdo es el que prepondera y tiene mayor aceptación entre la mayoría de individuos puede ser por la textura tan suave y sabrosa de la carne y como el ácido contrasta tan bien con la grasa natural de la misma, por el contrario del sudado de lengua que fue el que menor aceptación por parte de los encuestados posiblemente por lo rugoso de la proteína además de su olor característico y como no es la comida que se "consume normalmente".

\section{Conclusiones}

- Se determinó que la comida local manabita es caracterizada por un sinnúmero de elementos que la hacen única, empezando por la historia que le precede en los tiempos precolombinos donde los alimentos eran símbolo de espiritualidad, fertilidad y eran ofrendas a los dioses, el mestizaje y el sincretismo que hubo entre las técnicas e ingredientes de los indígenas hasta los alimentos y manufacturas que fueron traídos de Europa, a las preparaciones como los ingredientes que son usados por que estos también tienen una historia que marcan a la sociedad en la actualidad, elementos tan únicos que incluso son parte de la identidad cultural y genética de varios.

- Queda claro que la comida manabita es mucho más que solamente mariscos y pescado como la mayoría piensa, cliché que por lo cual turistas solo se enfocan en visitar y conocer los balnearios que existen en la provincia, sin embargo, la comida criolla manabita compone un elemento decisivo de la denominada "comida local" o "comida típica" por qué es la que ha mantenido a los campesinos y trabajadores a lo largo de generaciones y hasta la actualidad.

- Esta comida poco conocida y difundida guarda incluso más tradición y autenticidad que lo que los turistas conocen comúnmente porque como se mencionó anteriormente esto es lo que ha mantenido a la gente de comunidades trabajadoras del campo en donde los muchos y diferentes elementos de la tierra se han unido y han sido preparados para brindar un sustento diario a quienes los cultivaron y apreciaron sus bondades.

- Una cosa más que se denota es que como las personas en general desconocen ciertos ingredientes usados en la comida criolla manabita al inicio pueden estar algo reacios de probar dichas preparaciones, en donde elementos como las entrañas, la lengua específicamente, pueden resultar algo chocantes para algunos comensales, sin embargo al momento de degustar las preparaciones que incluyen el vinagre de plátano se dan cuenta que esta clase de preparaciones tienen más por ofrecer en el ámbito gastronómico no solo local sino a nivel del país. 


\section{Referencias bibliográficas}

Díaz, J. F. (2020). Análisis de la concentración de ácido acetatico de seis marcas de vinagre de manzana. Medicina naturista, 14 (2), 79-83.

Fernández, L., Rodríguez, Z., Pozo, J. \& Espinosa, J. (2016). Estrategias para el Fortalecimiento del Turismo Gastronómico en el Cantón Pastaza, Ecuador. Dialnet, 5(2), 119.

Folleco, J., Espini, C. \& Quintanilla, R. (2019). Reinventando la investigación en salud y educación para una sociedad transcultural (Vol. 101). Almería: Editorial Universidad de Almería.

Gómez, C., Dema, M. \& Sandoval, S. (2016). Etnocentrismo y comida típica regional: una caracterización de las preferencias y consumo de la población urbana de Sonora. Razón y palabra, 20(94), 513.

Jeambey, Z. (2016). Rutas Gastronómicas y Desarrollo local: Pasos revista de Turismo y Patrimonio Cultural, 14(5), 1188.

MINTUR. (2019). Portoviejo un destino gastronómico reconocido en el mundo. Ministerio de Turismo.

Molina, G., Palacios, P., \& Torres, O. (2018). Diagnóstico de la cultura alimentaria de la parroquia urbana de. Dossier académico, 104.

Sandhusen, R. L. (2002). Mercadotecnia. Continental.

Teneda, W., \& Milla, S. (2018). Estudio para determinar el mercado potencial del vinagre de frutas naturales: Aplicación en el Ecuador. Akadem, 93.

Unigarro, C. (2015). Sistemas y patrimonio alimentarios. Transculturaciones en el caso ecuatoriano. Antropología Cuadernos de Investigación (15), 28.

Valcárcel, D., \& Venegas, A. (2015). La comida típica dentro de la internalización de la oferta gastronómica en Bogotá. Turismo Sociedad, 188.

Velasteguí, E., \& Rodríguez, F. (2017). Vinagre artesanal como impacto socioeconómico medio educativo. Visionario Digital, 1(1), 1.

\section{LCiencia}


El artículo que se publica es de exclusiva responsabilidad de los autores y no necesariamente reflejan el pensamiento de la Revista Conciencia Digital.

\section{Ciencia}

El artículo queda en propiedad de la revista y, por tanto, su publicación parcial y/o total en otro medio tiene que ser autorizado por el director de la Revista Conciencia Digital.
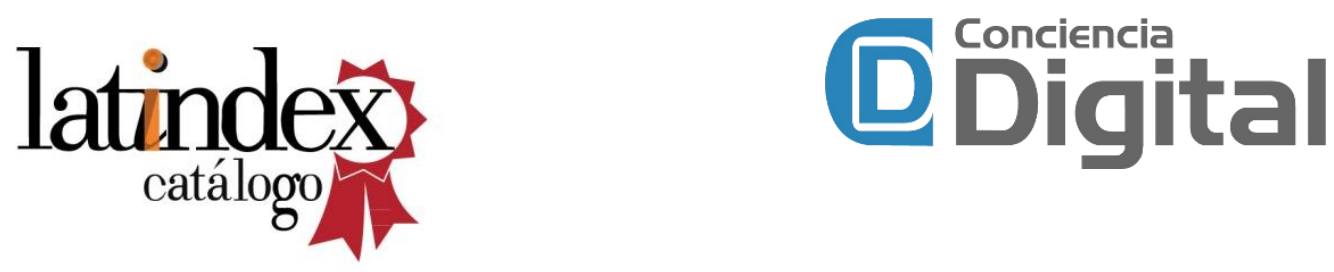

Indexaciones

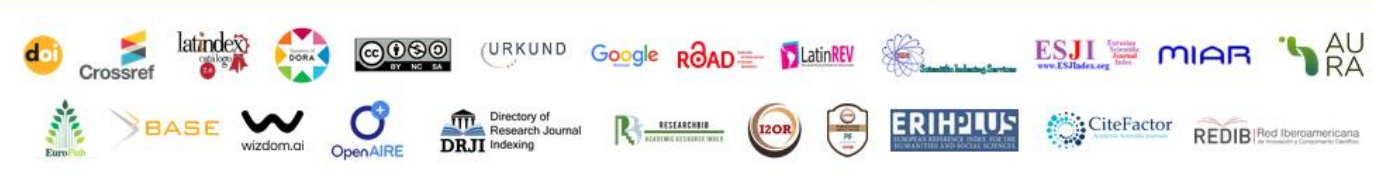

